\title{
Websites de Redes Sociais e Implicações para Interações e Aprendizagem Informais
}

\author{
Simone C.O. Conceição, University of Wisconsin-Milwaukee, \\ simonec@uwm.edu \\ Nicole Weber, University of Wisconsin-Milwaukee, nicolea5@uwm.edu \\ M. Julia Baldor, University of Wisconsin-Milwaukee, mjbaldor@uwm.edu
}

\begin{abstract}
Resumo. Este estudo emprega análise de conteúdo para obter uma compreensão aprofundada de interações em grupos de redes sociais on-line. Resultados indicam que o espaço social on-line pode criar e manter laços sociais e culturais entre os membros de uma comunidade informal. Identidade social é reconhecida através de mensagens de apresentações, compartilhamento de recursos e anúncio de eventos sociais. Identidade cultural é evidenciada através de mensagens envolvendo tópicos relacionados a relatos sociais, poemas, política, espiritualidade e noticias. Participação neste ambiente social em rede vai além das fronteiras sociais e culturais de interações. Esse espaço social também serve como um condutor para interações informais de seus membros, formação de identidade, apoio mútuo e aprendizagem informal.
\end{abstract}

Palavras chave: Redes sociais, laços sociais e culturais, identidade, aprendizado informal, interações.

\begin{abstract}
This study employed content analysis to develop an in-depth understanding of web-based social networking group interactions. Findings indicate that an online social space can create and maintain social and cultural ties among members of an informal community. Social identity was acknowledged through introductory postings, sharing of resources, and announcement of social events. Cultural identity was evident through postings involving topics related to cultural stories, poems, politics, spirituality, and news. Participating in this social networking environment went beyond fostering social and cultural networking exchanges. This social space also served as a conduit for informal networking, identity formation, supporting each other, and learning.
\end{abstract}

Key words: Social networks, social and cultural, informal learning, interactions.

\section{Introdução}

Viver num outro país exige dos imigrantes assimilar a cultura do novo ambiente. Geralmente, a mudança para este novo ambiente cria uma sensação de ser diferente e aumenta o sentimento de isolamento, aculturação e estresse (ou stress). Muitas pessoas quando imigram para outro país encontram barreiras de comunicação e formação de novos relacionamentos. Assim, elas procuram conexões sociais para ultrapassar estas barreiras. Os ambientes de redes sociais (tais como os websites Facebook, Orkut ou MySpace) têm se tornado um ambiente comum para conexões sociais de imigrantes porque eles ajudam as pessoas a se sentirem como se pertencessem a um grupo através do compartilhamento de experiências similares. Esses ambientes podem ajudar as pessoas a estabelecer novos relacionamentos, aprender a colaborar com outros, a melhorar suas habilidades de comunicação e promover o crescimento pessoal e a aprendizagem. 
Os websites que servem de base para as redes sociais têm o potencial de promover o desenvolvimento de novos relacionamentos através do acesso e da participação em comunidades on-line. Através das comunidades de rede, os membros podem desenvolver relacionamentos e participar de comunidades on-line que os introduzem a novos e diferentes tipos de pessoas. Os membros podem compartilhar experiências e conhecimentos e ganhar reconhecimento através das interações na comunidade (Skiba, 2007).

Antigamente, as tecnologias de rede tinham um usuário passivo. Hoje, os membros das redes sociais estão envolvidos ativamente com outras pessoas na construção, publicação e trocas de idéias. Pela participação ativa numa comunidade de rede social, os membros se envolvem em interações sociais, ouvindo uns aos outros e fornecendo aos demais comentários sobre os assuntos em questão (Penuel \& Riel, 2007). Hoje em dia, as pessoas que usam os ambientes das redes sociais têm um papel mais ativo. Elas geralmente tendem a manter laços com pessoas que conhecem face a face no ambiente on-line. Tem sido evidente que quando as pessoas se deslocam de lugar para lugar, continuam ativas e fazem sua rede de relacionamento através de sites de redes sociais on-line (Vivian \& Fay, 2003).

As interações em redes sociais podem prover seus membros de um senso de poder quando controlam suas interações com ferramentas on-line e com outras pessoas. Quando os membros das redes sociais interagem num ambiente on-line eles têm o potencial de aprender como ser e agir no mundo e descobrir quem são eles realmente, criando, através das interações com os membros do grupo, uma identidade dentro da comunidade da rede social.

\section{Metodologia}

Este estudo empregou a análise de conteúdo para obter uma compreensão aprofundada de um ambiente de rede social on-line em uso por um grupo de brasileiros nos Estados Unidos. O site do grupo Yahoo "Brasil_em_Wi" foi propositadamente selecionado porque é usado por brasileiros no Estado de Wisconsin com a meta de manter contato com outros brasileiros, anunciar eventos locais e partilhar relatos sociais e culturais. A comunidade também tem membros não brasileiros que são interessados na cultura brasileira. Estatística descritiva foi usada para identificar informações sobre as características do grupo como a frequência de participação dos membros e os tipos de mensagens postadas. A análise do website foi conduzida para observar os tipos de participações em que seus membros estão engajados de forma a explorar temas emergentes e categorias.

\section{Framework Conceitual}

A análise de dados foi baseada no framework para a Criação e Manutenção de Redes Sociais adaptado de Vivian e Sudweeks (2003). Neste framework o espaço social é o ambiente do grupo Yahoo. Nesse espaço social, os membros da comunidade se conectam a pessoas que estão geograficamente separadas, mas interconectadas entre si. Certos membros podem ter se mudado para outra área, mas continuam a ser membros da rede social on-line. Isto significa que este espaço social é um site sem lugar fixo, mas apesar disso, é de vital importância para seus membros.

Assim como espaços físicos, neste espaço social os membros da comunidade se encontram virtualmente, conversam entre si, trocam fotos, músicas e poesias e se envolvem em muitas outras formas de comunicação. Participantes deste site, como membros da comunidade, formam e mantêm relacionamentos criando uma comunidade informal neste ambiente virtual. Esta construção de relacionamentos entre brasileiros e 
amigos cria uma comunidade e forma e reforça o senso de "pertencer". Figura 1 mostra a representação gráfica do framework adaptado para nosso estudo.

Figura 1 Framework Adaptado de Vivian e Sudweeks (2003)

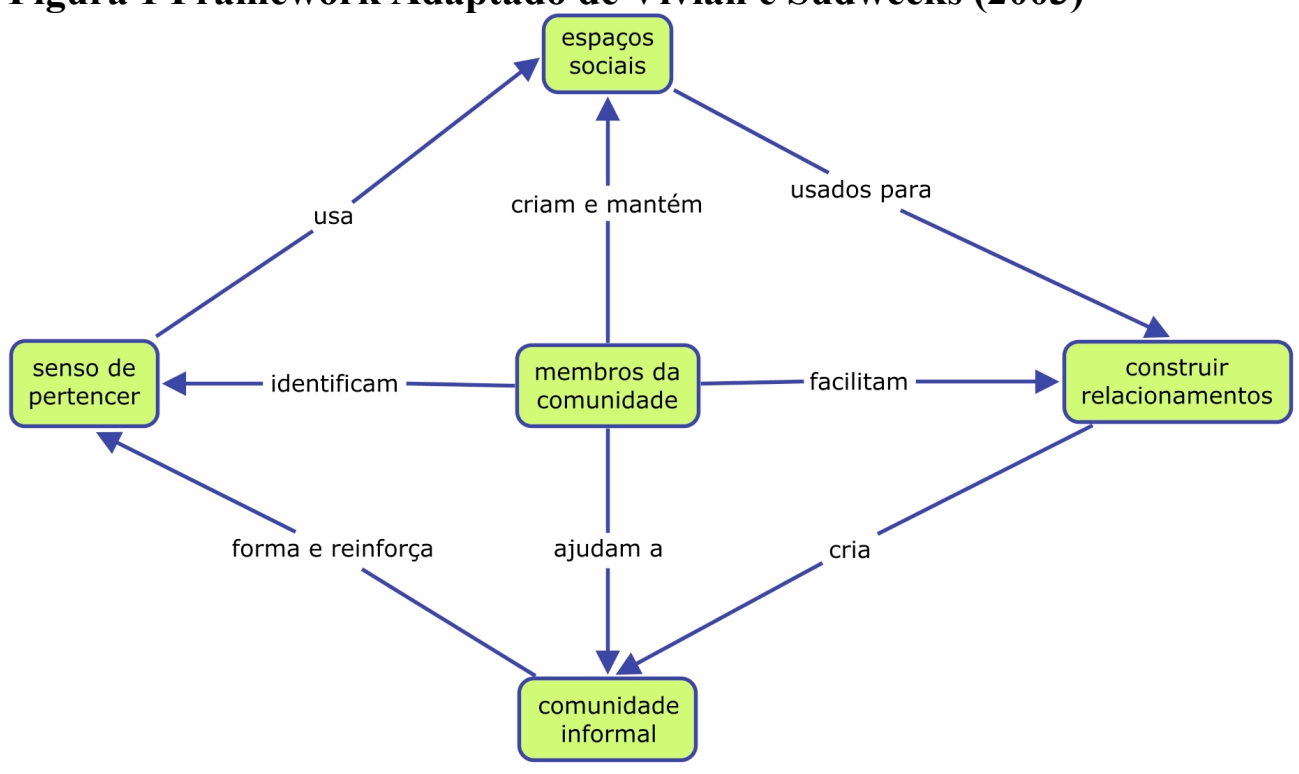

\section{Resultados}

\subsection{Características do Espaço Social Yahoo Group "Brasil_em_Wi”}

O espaço social no website do Yahoo Group Brasil_em_Wi, formado em agosto de 2001, gerou 1.409 mensagens e teve 239 membros até $1 \overline{2}$ de março de 2009. A língua principal do website é o português, entretanto, ocasionalmente são postadas mensagens em inglês. A inscrição de membros é aberta a qualquer interessado na cultura brasileira, não sendo possível diferenciar entre membros brasileiros e não brasileiros. As mensagens são tipicamente na forma de anúncios com propósitos definidos. Os membros podem enviar mensagens e incluir anexos aos e-mails. $\mathrm{O}$ foco das interações é centrado nos eventos sociais e culturais vindouros. A adesão a este Yahoo Group exige a aprovação por um moderador, mas as mensagens não exigem aprovação. Mensagens inapropriadas são bloqueadas pelo moderador ou vão para uma área de spam do website. Devido ao foco do espaço social em interações com propósitos definidos, as mensagens são menos emocionais quando enviadas para todo o grupo. $\mathrm{O}$ espaço social do Yahoo Group tem um design sólido e permanente e contém características de um sistema de gerenciamento de conteúdo, pois inclui arquivos, lista de membros inscritos, links, banco de dados, pesquisas e calendário. Embora muitas destas características estejam incluídas no website, nem todas são usadas regularmente. Tabela 1 resume as características do Yahoo Group Brasil_em_Wi.

Tabela 1 Resumo das Características do Yahoo Group Brasil_em_Wi

\begin{tabular}{|l|l|}
\hline Caracteristica & Yahoo Group Brasil_em_Wi \\
\hline Língua usada & Português, ocasionalmente inglês \\
\hline Tipo de interação & Com e entre brasileiros nos Estados Unidos \\
\hline Tipo de anúncios & Proposicionais \\
\hline Finalidades de uso & $\begin{array}{l}\text { Comunicação de eventos, atividades locais ou notícias } \\
\text { informativas. Grupo fornece um senso de conforto baseado } \\
\text { no nome do grupo e nas finalidades. }\end{array}$ \\
\hline Natureza da Interação & Social e cultural \\
\hline
\end{tabular}

V. $9 \mathrm{~N}^{\mathrm{o}} 1$, julho, 2011 


\begin{tabular}{|l|l|}
\hline Caracteristica & Yahoo Group Brasil_em_Wi \\
\hline Foco da Interação & Eventos sociais e culturais vindouros \\
\hline Nível de exposição & $\begin{array}{l}\text { Membros inconvenientes podem ser bloqueados, } \\
\text { mensagens inapropriadas vão para spam; membros } \\
\text { precisam ser aprovados pelo moderador }\end{array}$ \\
\hline $\begin{array}{l}\text { Natureza das mensagens } \\
\text { individuais }\end{array}$ & Menos emocionais, mais propositivas \\
\hline Interatividade & $\begin{array}{l}\text { Comunicação interativa pública ou privada entre membros } \\
\text { dentro do Yahoo Group }\end{array}$ \\
\hline Design da rede social & $\begin{array}{l}\text { Sólido, permanente, parte de um sistema de gerenciamento } \\
\text { de conteúdo }\end{array}$ \\
\hline
\end{tabular}

\subsection{Participação dos Membros da Comunidade}

Análise estatística do website mostra que os membros têm aderido continuamente ao Yahoo Group desde 2001, mas teve a adesão de cerca de metade dos seus membros (49\%) entre os anos de 2006 e 2008. Quando os membros enviam mensagens ao website outros membros podem vê-las de dois modos: no site do Yahoo Group ou por e-mail. A maioria dos membros (93\%) recebe mensagens de e-mail que contém mensagens enviadas por outros membros, enquanto apenas 5\% escolhem receber as mensagens de formas diferentes, como um resumo diário onde as mensagens são resumidas numa base diária ou apenas recebem mensagens que são consideradas notas especiais ou usadas como anúncios. Mais da metade dos membros (56\%) não enviou nenhuma mensagem ao website, enquanto o moderador enviou mais de 100 mensagens.

\subsection{Construindo Relacionamentos através de Interações}

Análise do conteúdo das mensagens mostra claramente que os membros da comunidade facilitam a construção do relacionamento através de interações sociais e culturais de forma informal. Mensagens sociais são aquelas em que os membros se apresentam para o grupo, compartilham recursos e anunciam eventos sociais. Numa mensagem, uma brasileira estudando em Wisconsin solicitou ajuda dos membros do website para completar uma pesquisa que ela necessitava para preencher uma tarefa de aula. Num outro caso, um membro contatou a comunidade em benefício de um brasileiro que estava se mudando para Wisconsin e necessitava conseguir um lugar para morar. Também durante os primeiros dias de janeiro de 2009 um membro enviou uma mensagem desejando a todos os membros um feliz Ano Novo. Tabela 2 fornece exemplos adicionais de mensagens com foco na identidade social.

Tabela 2 Exemplos de Tópicos sobre Identidade Social

\begin{tabular}{|l|l|}
\hline Temas & Tópicos sobre Identidade Social \\
\hline Apresentações & Apresentação para o resto da lista \\
\hline $\begin{array}{l}\text { Recursos } \\
\text { compartilhamento de }\end{array}$ & $\begin{array}{l}\text { Baby-sitter, aluguel de carro, serviços de tradução, vôos } \\
\text { econômicos, oportunidades de emprego, custos de correio para } \\
\text { o Brasil, restaurantes brasileiros, voluntários para eventos } \\
\text { locais, informações sobre consulado brasileiro, ajuda a outros } \\
\text { na mudança para a região }\end{array}$ \\
\hline Anúncios ou convites & $\begin{array}{l}\text { Recitais de música, apresentações de dança, carnaval, esportes } \\
\text { (por exemplo: futebol e capoeira), dia de ação de graças } \\
\text { brasileiro, brasileiros que se apresentam na área, eventos de } \\
\text { levantamento de fundos, festival de filmes latino americanos, }\end{array}$ \\
\hline
\end{tabular}

V. $9 \mathrm{~N}^{\mathrm{o}} 1$, julho, 2011 


\begin{tabular}{|l|l|}
\hline Temas & Tópicos sobre Identidade Social \\
\hline & festivais de música. \\
\hline
\end{tabular}

Mensagens culturais incluem tópicos relacionados com o Brasil ou com a cultura brasileira, tais como relatos, poesias brasileiras, política e notícias. Um membro compartilhou com a comunidade uma apresentação PowerPoint da beleza do rio Amazonas, suas características, fauna e flora. Outro membro relembrou à comunidade sobre a data de um show de rádio, que abrangia cultura brasileira e música. $\mathrm{O}$ dia da Proclamação da Independência brasileira, por exemplo, foi comemorado com samba e lições de dança. É importante salientar que nem todas as mensagens trocadas foram exclusivamente relacionadas à cultura brasileira. Os membros deste grupo querem manter sua identidade cultural como brasileiros, entretanto, também estão engajados na nova comunidade. Mensagens incluem também organizar um encontro num estacionamento para irem juntos assistir a um importante jogo de baseball, combinadas com links para material sobre política americana e mensagens ambientais. Tabela 3 apresenta exemplos de tópicos adicionais com foco na identidade cultural.

Tabela 3 Exemplos de Tópicos sobre Identidade Cultural

\begin{tabular}{|l|l|}
\hline Temas & Tópicos sobre Identidade Cultural \\
\hline Relatos e Poesias & $\begin{array}{l}\text { Compartilhamento de PowerPoint sobre fauna e flora do rio } \\
\text { Amazonas, lembrete de programa de rádio sobre cultura e música } \\
\text { brasileira, compartilhamento de poemas escritos por poetas } \\
\text { brasileiros }\end{array}$ \\
\hline Política & $\begin{array}{l}\text { Discussão sobre eleições, comentários depois de debates no } \\
\text { Brasil, entrevistas com cidadãos brasileiros }\end{array}$ \\
\hline Espiritualidade & $\begin{array}{l}\text { Orações, serviços da igreja, solicitação de orações para membro } \\
\text { da família doente }\end{array}$ \\
\hline Notícias & Resultados dos jogos de futebol, resultados das eleições no Brasil \\
\hline
\end{tabular}

\subsection{Sentimento de Pertencer a Comunidade Informal}

O sentimento de pertencer através das interações com outros membros da comunidade foi evidente entre os membros da comunidade. O website permitiu que os membros se sentissem aceitos, confiassem uns nos outros e se confortassem mutuamente. Os membros foram capazes de expressar suas visões políticas e espirituais através de seus relatos. Baseado na análise do número de mensagens, observamos que a maior quantidade de mensagens no website foi enviada durante o mês de outubro de 2006. Isso deveu-se à próximidade do período eleitoral no Brasil, de forma que a comunidade trocava idéias e opiniões e compartilhava os acontecimentos mais atualizados sobre as eleições.

\section{Discussão}

De acordo com Fragoso (2006), os brasileiros são "um povo que se orgulha de suas relações de amizade, tanto quanto o fazem na cultura nacional, que apresenta uma multiplicidade de hibridismo cultural que, de fato, permeiam e constituem a experiência do Brasil” (p. 267). Os membros do Yahoo Group Brasil_em_Wi trabalham juntos para criar um espaço social on-line "onde as pessoas podem se encontrar, comunicar-se com outros e assimilar" a vida no Estado de Wisconsin (Vivian \& Sudweeks, 2003, p. 1432). Os membros usam o website para se conectar com outros membros, que são brasileiros vivendo na área ou indivíduos interessados na cultura brasileira, para divulgar eventos e 
compartilhar atividades que os permitam celebrar a cultura brasileira e aprender a cultura de Wisconsin.

O espaço social criado pelo ambiente social de rede é trans-territorial (Vivian \& Sudweeks, 2003), tanto por ser centralizado na experiência de pessoas vivendo na área de Wisconsin, nos Estados Unidos, ou cercanias, quanto por ser um espaço brasileiro fora dos limites geográficos do Brasil. Embora muitos membros morem em Wisconsin, suas residências não são próximas entre si, esses membros se comprometem a permanecerem conectados. O ambiente de rede social on-line provê um espaço virtual para este objetivo. A falta de um espaço físico brasileiro, tal como um centro cultural onde as pessoas possam se encontrar, faz com que os membros respondam criando e mantendo um espaço cultural, onde brasileiros que estão em Wisconsin possam se encontrar, bater papo, compartilhar informações e manter-se conectados entre si e a identidade cultural brasileira.

Espaços sociais on-line, tais como os websites de redes sociais, criam uma comunidade informal onde os membros podem utilizar este espaço social para criar e manter relacionamentos, bem como fazer parte de um grupo de pessoas de comunidades passadas, atuais e futuras. Esse grupo particular focado nos brasileiros que vivem em Wisconsin apóia um ao outro como uma comunidade de prática.

De acordo com Wenger (1999), essas comunidades de prática existem e prosperam devido à incorporação de três dimensões: o compromisso mútuo, a empresa conjunta e um repertório compartilhado. É importante que os membros da comunidade tenham um compromisso mútuo que está ligado à negociação de ações ou idéias comuns. No Yahoo Group Brasil_em_Wi isto ocorre quando os membros fazem perguntas e apoiam uns aos outros, pessoas com experiência respondem a perguntas com soluções práticas baseadas em recursos reconhecidos. Mesmo que alguns membros possam assumir um papel mais ativo enquanto outros enviam poucas mensagens, todos os membros se engajam na leitura das mensagens, que podem ser vistas como forma de seu próprio engajamento.

A segunda faceta, a empresa conjunta, indica que a comunidade como tal não é auto-contida que opera isoladamente em seu prol. Sem dúvida, ela existe e se desenvolve em conexão com outros espaços que poderiam ser providos pelos membros da comunidade conectados a outros recursos históricos, sociais, culturais e institucionais. Finalmente, o repertório compartilhado "inclui rotinas, palavras, ferramentas, meios de fazer as coisas, histórias, gestos, ações ou conceitos que a comunidade tenha produzido ou adotado no curso de sua existência, e os quais tenham se tornado parte de sua prática" (p. 83). Membros do website de rede social, ao longo do tempo, trabalham juntos para negociar normas de grupo. No caso, mensagens podem ser enviadas em português ou inglês e tornar-se um sistema de apoio para os outros membros.

O compartilhamento de recursos e interações culturais são muito importante para o imigrante que deixou sua comunidade natal para trás, mudando-se para outro país. Esta mudança de ambiente deixa os indivíduos isolados na medida em que já não estão mais em sua terra natal e ainda não fazem parte da nova comunidade. Comunicações através do website provêem a esses imigrantes um "novo senso de comunidade que transcende o estado de nação" (Falk, 1988, p. 288). Desta forma, eles estão aptos a fortalecer sua identidade como brasileiros enquanto estão nos primeiros estágios da formação de sua identidade brasileiro-americana.

Membros do espaço on-line recebem todas as mensagens e podem escolher quais querem ler. Eles podem participar não somente lendo as mensagens, mas também enviando materiais em anexo. Membros decidem quais assuntos e tópicos desejam 
discutir ou ignorar. Esta habilidade de participar no design e conteúdo do website dá poder aos membros e controle sobre a natureza de suas interações. Este poder de controle engaja os membros no diálogo e troca de recursos, idéias e informações. Através das interações virtuais, os membros têm a oportunidade de estabelecer comunicação e construir novos relacionamentos.

Enquanto muitas pessoas poderiam ver esses espaços on-line como comunicação entre pessoas que não se "conhecem" entre si, este não é o caso com esse grupo. $\mathrm{Na}$ maioria dos casos, os membros deste grupo vêem mensagens que chegam através de outros membros que tenham conhecido, tenham conexão com outros membros e que fazem parte de sua rede social estendida (Boyd \& Ellison, 2007, p. 2). Por isso, o grupo é usado como "um fórum para discussões e interações" e cria "cultura em si, geralmente ofuscando as barreiras entre o mundo real e virtual" (Gunawardena, 2009, pp. 6-7). Entretanto, este espaço é usado para compartilhar eventos, tanto culturais (por exemplo, o carnaval brasileiro) e sociais (por exemplo, convidar outros membros para um recital de violino), bem como para oportunidades de emprego, esportes, música, política e comentários espirituais que os permitem sentir-se conectados ao Brasil e à Wisconsin.

Nosso estudo indica que os membros do grupo, apesar da falta de interação face a face, apreciam o espaço social que eles ajudam a criar através do website. De acordo com Wellman et al. (1996), esses membros "encontram um apoio social, acompanhamento e sentimento de pertencer ao grupo" (p. 220), mesmo quando o website é composto em sua maioria por conhecidos e pessoas que mal se conhecem. É importante para estes indivíduos que são imigrantes que tenham um sentimento de ajuste ou de pertencerem ao ambiente. Isto lhes dá um sentimento de aceitação e conforto num momento em que, vivendo num país estrangeiro, poderiam se sentir sobrecarregados emocionalmente. Ao mesmo tempo o website traz a eles a oportunidade de buscar, não apenas as necessidades sociais de relacionamento, mas também atividades culturais e educacionais num ambiente de aprendizagem auto direcionado.

Logo que brasileiros se mudam para Wisconsin, pode haver um sentimento de isolamento e de solidão associado com o abandono de sua cultura e a inserção de uma nova. Entretanto, com o advento das novas tecnologias, tais como o Yahoo Group e outros websites de redes sociais, os indivíduos podem, agora, se mudar e levar suas redes sociais consigo (Vivian \& Sudweeks, 2003). Também, esses websites fazem com que a criação de novas ligações a outros brasileiros que já estão vivendo em Wisconsin e que compartilham suas experiências e eventos, se torne mais fácil, estendendo amizades e contribuindo para um importante senso de pertencer a uma nova comunidade. Interessante observar que estes websites provêm um espaço para os membros exporem e apoiarem seus companheiros brasileiros, respondendo a assuntos e questões sobre notícias do Brasil e de Wisconsin, eventos e recursos. Isto permite que os membros tenham oportunidade de acessar em primeira mão conhecimentos e recursos compartilhados por membros da comunidade com mais experiência (Boule, 2008; Chapman, Ramondt, \& Smiley, 2005). Como estas conexões de conhecimento são pessoais, elas levam a um sentimento muito mais forte de pertencer à comunidade.

\section{Implicações para as Interações Informais}

Usando as ferramentas de redes sociais, indivíduos podem melhorar suas habilidades de comunicação, aprender a negociar normas sociais e se expor a múltiplas experiências culturais. Habilidades de comunicação são componentes integrantes de uma sociedade baseada no conhecimento. Aprender como operar dentro de uma rede social exige conhecimento das normas de conduta e comportamento apropriado. Tudo isso leva ao conhecimento de como participar numa sociedade multicultural.

A importância das interações em comunidades virtuais não deve ser minimizada. V. $9 \mathrm{~N}^{\mathrm{o}} 1$, julho, 2011 
Embora estas comunidades sejam intangíveis, devido a sua natureza, indivíduos que delas participam são pessoas reais com vidas reais, que se sentem pessoal e emocionalmente conectados a outros. Essas comunidades podem ajudá-los a incrementar seus sentimentos de identidade social e cultural e geralmente redirecionar o sentimento de isolamento.

Linguagem e símbolos culturais podem preencher o espaço deixado vago pela ausência de sinais físicos. Eles não só identificam culturas individualmente, mas também o grupo aos quais eles pertencem. O nível de exposição no grupo é, de certa forma, controlado pelos membros do grupo e pela tecnologia que captura mensagens de spam; entretanto, é através das normas de grupo que mensagens inapropriadas são melhor controladas.

\section{Conclusões}

Em uma época em que as comunicações mediadas por computador atuam como partes integrantes de nossas vidas, é importante reconhecer que as comunidades informais também podem impactar no aprendizado informal. Esses ambientes de aprendizado em rede podem afetar o desenvolvimento e crescimento do indivíduo. Nosso estudo mostra que um espaço social on-line pode promover a identidade social e cultural de seus membros numa comunidade informal. O Yahoo Group Brasil_em_Wi é crucial para manter a identidade social de seus membros no papel de amigos, trabalhadores ou estudantes. Através do grupo, os membros são capazes de chegar e fazer contato para criar, manter e desenvolver relacionamentos. Este canal de comunicação é crucial para os imigrantes que facilmente podem se sentir isolados e sobrecarregados emocionalmente pelas diferenças do novo ambiente, especialmente durante o primeiro estágio de suas vidas no país hospedeiro.

Devido às responsabilidades de emprego, educação e família é difícil para estes recém-chegados visitar amigos e conhecidos, se eles os têm. $\mathrm{O}$ web site provê um espaço social bastante necessário e conveniente a um click dos outros membros. $\mathrm{O}$ grupo comprovou que é crítico para encontrar emprego e moradias, partilhar recursos (como produtos brasileiros), buscar serviços espirituais e prover apoio psicológico e formar amizades.

Klamma et al. (2007) afirmam que "Aprendizado não é só restrito a sala de aula e ao ensino formal dentro das instituições de aprendizagem; é uma atividade na qual acontece ao longo de toda a vida, no trabalho, no lazer e em casa" (p. 72). Redes sociais on-line são agora facilitadoras desse aprendizado informal. Nesse estudo essa rede social on-line foi o elemento condutor para interações informais de seus membros, formação de identidade, apoio mútuo e aprendizagem informal.

\section{Agradecimentos}

Agradecemos ao Centro Roberto Hernandez da Universidade de WisconsinMilwaukee pelo apoio financeiro que tornou este estudo possível. Também agradecemos a Roberto Cabral de Mello Borges por traduzir nosso trabalho para o português, Aline O. da Conceição por prover comentários, e Les Johnson por criar o gráfico do framework.

\section{Referências}

Boule, M. (2008). Going with the flow. School Library Journal, 54(11), 50-52. 
Boyd, D.M., \& Ellison, N.B. (2007). Social network sites: Definition, history, and scholarship. Journal of Computer-Mediated Communication, 13(1), 210-230.

Chapman, C., Ramondt, L, \& Smiley, G. (2005). Strong community, deep learning: exploring the link. Innovations in Education and Teaching International, 42(3), 217230.

Falk, J. (1988). The Meaning of the Web. The Information Society, 14, 285-293.

Fragoso, S. (2006). WTF a crazy Brazilian invasion. Proceedings cultural attitudes towards communication and technology. Murdoch University, Australia, 255-274.

Gunawardena, C. N., Hermans, M. B., Sanchez, D., Richmond, C., Bohley, M., \& Tuttle, R. (2009). A theoretical framework for building online communities of practice with social networking tools. Educational Media International, 46(1), 3-16.

Klamma, R., Chatti, M., Duval, E., Hummel, H, Hvannberg, E., Kravcik, M., Law, E., Naeve, A., \& Scott, P. (2007). Social software for life-long learning. Educational Technology and Society, 10(3), 72-83.

Penuel, W. R., \& Riel, M. (2007). The 'new' science of networks and the challenge of school change. Phi Delta Kappan, 88, 611-615. Acessado em 25/09/2007 em EBSCOhost.

Skiba, D. J. (2007). Nursing education 2.0: Poke me. Where's your face in space? Nursing Education Perspectives, 28, 214-216.

Vivian, N., \& Fay Sudweeks. (2003). Social networks in transnational and virtual communities. Informing Science, Junho 2003.

Wellman, B., Salaff, J., Dimitrove, D., Garton, L., Gulia, M., \& Haythornthwaite, C. (1996). Computer Networks as Social Networks: Collaborative Works, Telework, and Virtual Community. Annual Review of Sociology, 22, 213-238.

Wenger, E. (1999). Communities of practice: Learning, meaning, and identity. New York: Cambridge University Press. 